\title{
Contraceptive use and associated factors among sexually active HIV positive women attending ART clinic in FHRH in Bahir Dar, north west, Ethiopia, 2018. Facility based cross-sectional study.
}

tilksew ayalew ( $\sim$ jonnyayu@gmail.com )

Bahir Dar University

Tilahun Tewabe

Bahir Dar University

Abdulhakim Abdanur

Bahir Dar University

Demoze Jenbere

Bahir Dar University

Mastewal Ayehu

Bahir Dar University

Girma Talema

Bahir Dar University

\section{Research}

Keywords: Contraceptive use, Contraception, Human immune virus positive women, Bahir Dar, North west Ethiopia.

Posted Date: December 24th, 2019

DOI: https://doi.org/10.21203/rs.2.19540/v1

License: (c) (i) This work is licensed under a Creative Commons Attribution 4.0 International License. Read Full License 


\section{Abstract}

Abstract Back ground: Contraception helps prevent unplanned pregnancies and mother to child HIV transmission among human immune virus positive women. Contraceptive use status and associated factors were not well addressed in the study area. This study aimed to assess contraceptives use and associated factors among HIV positive sexually active women at anti-retroviral therapy clinic in Felege Hiwot Referral Hospital, Northwest Ethiopia. Method : A facility based quantitative cross-sectional study was conducted from June 01 -30, 2018, among 308 randomly selected sexually active HIV positive women of reproductive age in Felege Hiwot Referral Hospital anti-retro viral treatment clinic. A pre-tested interviewer-administered questionnaire was used to collect data. Data were analyzed using SPSS version20. Descriptive statistics were used to summarize socio-demographic characteristics of participants. A multivariate logistic regression analysis method was employed and odds ratio with $95 \%$ confidence interval was used to control possible confounders. Statistical significance was declared at pvalue $<0.05$. Results: The current study revealed that overall contraception use among sexually active HIV positive women was $38.3 \%$ (95\% Cl: $32.5 \%-43.5 \%$ ). Women with age range of $15-34$ years old (AOR $=3.089,95 \% \mathrm{Cl}: 1.591-5.999)$, HIV status disclosure to sex partner, $(\mathrm{AOR}=2.75995 \% \mathrm{Cl}: 1.142-6.663)$, previous contraception utilization experience; $(A O R=3.361,95 \% \mathrm{Cl}: 1.677-6.736)$, Sexual activity in the last six months (AOR5.451, 95\%Cl: 2.724-10.908) and had drinking habit (AOR=4.351, 95\%Cl: 1.824-10.379) were the main predictors of contraceptive use. Conclusion: Contraceptive use was low in the current study area. Efforts should be strengthened to increase contraception use among human immune virus positive women. Anti-retro viral treatment and family planning services should be integrated to increase contraceptive use uptake in the study area. Keywords: Contraceptive use, Contraception, Human immune virus positive women, Bahir Dar, North west Ethiopia.

\section{Introduction}

Although global community is working to end HIV/AIDS epidemic by 2030, it remains a major global epidemic in post millennium development era. It remains the leading cause of morbidity and mortality throughout the world. Since the start of the epidemic, around 76.1 million peoples infected and 35 million people died from AIDS (Acquired Immunodeficiency Syndrome) related illness[1]. Globally in 2017, there were 36.9 million people living with HIV; 18.2 million women of reproductive age group and 1.8 million were children under 15 years old. There were also a total of 1.8 million new infection and 940,000 AIDS related death in the same year. [2].

Eastern and southern Africa including Ethiopia remains the region most affected by the HIV epidemic, accounting for $45 \%$ of the world's HIV infection and $53 \%$ of people living HIV globally. Adolescent girls and young women continue to face disproportionately high risk of HIV in the region[2].Sub-Saharan Africa (SSA) contributed $76 \%$ of total of HIV-infected people,76\% of a total of new HIV infection and $75 \%$ of a total of HIV/AIDS related deaths in 2015[3]. 
As one of the sub-Saharan country, the scenario in Ethiopia is similar. In Ethiopia, the HIV epidemic has remained a major public health problem, largely affecting women of reproductive age group[4]. At the end of 2017, there were an estimated total 722,248 people infected with HIV, 22,827 new HIV infection and 14,872 annual AIDS related deaths. In the same year, an estimated HIV prevalence in the general population was at 1.5 percent[5].

The epidemic is well established in the urban areas of the country .According to Ethiopian populationbased HIV impact assessment (EPHIA2017-2018), the annual incidence of HIV among adult age groups (15-64) years in urban Ethiopia is $0.06 \%$. Prevalence of HIV among adult age $15-64$ years in urban Ethiopia is $3.0 \%$; $4.1 \%$ among women and $1.9 \%$ among men. Prevalence of HIV among children ages $0-$ 14 years in urban Ethiopia is $0.3 \%$, the same among both sexes. Viral load suppression among HIVpositive adults ages $15-64$ years in urban Ethiopia is $70.1 \%: 71.7 \%$ among women and $66.8 \%$ among men[6].

Voluntary family planning a key intervention for health and development by enabling women and couples to decide number, timing and spacing of births. Sexually active women can do this by using different contraceptive methods. Reducing maternal mortality, child mortality, abortion and transmission of HIV from mother to child are some of the health benefits of family $[7,8]$. Universal access for family planning and reproductive health is not the only path to sustainable development, but without addressing these issues achievement of other sustainable goals will be challenging [7].

Contraceptive is a cost-effective intervention for preventing mother to child HIV transmission [7]. The United Nations PMTCT strategy outlines four approaches necessary to cut mother-to-child transmission. Preventing unintended pregnancy in HIV infected woman is one of the recommended PMTCT strategy[9]. Study from U.S.-based Johns Hopkins University and the World Health Organization have found that only moderate reductions in unintended pregnancy rates among HIV-infected women would cut rates of HIVpositive births [9].

Ethiopia is the most populous country next to Nigeria with an estimated population of more than 100 million[4]. It has one of the highest fertility rate in Africa, with $45 \%$ of its population under- 15 years old. Ethiopia's strong investment in health sector have contributed to a significant progress over the last 10 years in increasing contraceptive use and reducing fertility rates. However, fertility and population growth rates remains high, at 4.1 and 2.6 percent [10].

Ethiopian health sector transformation plan has planned to increase proportion of contraceptive use from $42-55 \%$, to decrease total fertility rate from 4 to 3 percent, unmet need for family planning from $24-10 \%$ and adolescent age pregnancy rate from 12-3\% [11].However, the 2016 Ethiopian Demographics and Health Survey estimated only $36 \%$ of married women were using any of contraception which is lower than the HSPD II target [12].

Preventing unintended pregnancy among sexually active HIV positive women is cost effective approach to primary prevention of mother to child transmission of HIV. It is also a global public health priority for 
addressing the distracted state of maternal and child health in high HIV endemic areas like Ethiopia[13]. Every year, Meeting all unmet needs for modern contraceptive methods could avert 52 million untended pregnancies in developing region [14].

Meeting the family planning goals of women living with HIV through proper counseling and contraceptives services could optimize health outcomes for women, cut the potential HIV transmission to their children and help achieve an HIV free generation by $2020[15,16]$.Therefore, the aim of this study was to assess contraceptive use and associated factors among sexually active HIV positive women at ART clinic in Felege Hiwot Referral Hospital, Northwest Ethiopia, 2018.

\section{Methods}

Study design

This study employed a facility based cross-sectional study design using a quantitative method with structured interview administer questionnaire to obtain data from sexually active HIV positive reproductive age women attending ART clinic.

Study area, population and period

The study was conducted from June 1-30, 2018 at Felege Hiwot Referral Hospital. The hospital is a referral hospital which is found in Bahir Dar, capital city of Amhara regional state. The city is $564 \mathrm{~km}$ far away from Addis Ababa, the capital city of the Ethiopia. The Hospital provides different inpatient and outpatient services to the population of the region including ART and family planning services. The study population was all sexually HIV positive reproductive age women attending ART clinic of Felege Hiwot Hospital. There were about 6620 people living with HIV enrolled in the hospital during the study period. Out of these around $50.76 \%$ were reproductive age women. All of them were on HAART at the time of the study. In this study, we included non-pregnant sexually active women living with HIV in reproductive age group and who were available at the time of data collection.

Sample size determination and sampling procedure

Sample size was determined single population formula. Assumptions used in sample size calculation were, prevalence $(P)$ of contraceptive utilization $=76 \%$ [17], margin of error of $(d)=5 \%, Z a / 2=1.96$ at $95 \%$ confidence interval and non-response rate of $10 \%$. The total sample size was 308 .

First, we determined the numbers of the sexually active HIV positive women aged 15-49 years in ART clinic at Felege Hiwot Referral Hospital. Then, we developed sampling frame based on the number of participants. Finally, we selected the study participants by simple random sampling method i.e., lottery method.

Inclusion criteria 
- All sexually active HIV positive reproductive age women who receive ART treatment in Felege Hiwot hospital at the time of data collection.

\section{Exclusion criteria}

- Sexually active HIV positive reproductive age women with surgical removal of uterus, who had permanent contraception, who did not speak the local language or unable to communicate for any reason, were pregnant and who had a known infertility were excluded.

- Sexually active HIV positive women who were below the age of 18 who came to the facility without guardian or family were excluded from study for consent issue.

\section{Measurement}

The main outcome variable was self-reported contraceptive use six months earlier the data collection period. We defined contraceptive use as current use of any method by women to delay or avoid pregnancy for the last six months. We defined modern contraceptive methods as use of Pills, intra-uterine contraceptive device (IUD), injectable (Depo-Provera), implants (implanol or jaddel), male/female condom, diaphragm, permanent methods such as tubal ligation and hysterectomy to delay or avoid pregnancy. We defined consistent condom use as the use of female or male condoms in all vaginal sexual relationships with casual and/or steady partners.

Independent variables included in this study were age of woman, educational level, number of living children, drinking habit, partner HIV status, HIV status disclosure to partner, having stable sexual partner, earlier contraceptive use experience, condom use, and having sexual activity in the last six months.

Data collection and data quality assurance

Trained data collectors collected the data using structured interviewer administered questionnaire which we adopted from earlier studies $[17,18]$. The questionnaire had the following contents; Sociodemographic characteristics, reproductive and sexual characteristics, contraceptive use and HIV related health service factors. First, we prepared English version of the questionnaire then language experts translated it to local language (Amharic) and back to English to check consistency and accuracy. We recruited four diploma nurses and two Bachelor of Science nurses as data collectors and supervisors. Assigned supervisors closely managed the data collection process. In addition, we gave training for data collectors and supervisors on the overall content of questionnaire and data collection process for two consecutive days. We have carried out pre-test study on $5 \%$ of the calculated sample size of women in Adiss Alem Hospital ATR clinic which is out of study area and readjusted the questionnaire. We also reviewed medical records of participants to get clinical information on anti-retroviral treatment and CD 4 count.

Data processing and analysis 
The collected data were checked manually for completeness and consistency. Then, coded and entered into EPI Info version3.5.3 and transferred to SPSS version 20 for analysis. We used descriptive statistics to summarize socio-demographic characteristics of participants and prevalence of contraceptive use. To show factors associated with contraceptive use, we carried out binary logistic regression analysis at two levels. We performed univariate logistic regression to each independent variable with the outcome variable and then we included variables with $p$-value $<0.05$ in multivariate analysis. We measured strength of association using odds ratio, and $95 \%$ confidence intervals. Finally we declare statistical significance at $p$-value $<0.05$.

\section{Result}

All 308 sampled HIV positive women participated in the current study making a response rate of $100 \%$. The mean age of women was 26 years (SD \pm 4.08 ). Almost half all participants, $(52.2 \%)$ of women were aged between 15 and 29 years. More than two third (78.2\%) were from Orthodox Christianity. Regarding to educational status, $144(46.8 \%)$ women were not educated while 164 (53.2\%) were educated. Two third $(59.7 \%)$ of participants were not employed.

Majority of participants, $260(84.4 \%)$ had drinking habit. On the other hand, the result of this study revealed that $67(21.8 \%)$ of participants had previous child death. Almost half of participants $(45.5 \%)$ had wish to have more children in the future. Nearly half (55.8\%) of participants had stable sexual relationship. From all participants, $(73.1 \%)$ had disclosed their status to their sexual partner. One hundred, two- third (58.8\%) of participants had one partner during the last six months before the survey. Nearly one -fourth (24.4\%) participants had changed their regular sexual partner after their diagnosis. Reasons for changing partner were; death of partner (25.3\%), divorce (34.7\%) and spousal rejection (40\%) (Table 1 ).

Prevalence of contraceptive use in the study area was $38.3 \%$ ( $95 \% \mathrm{Cl}: 32.5 \%-43.5 \%)$. Regarding to contraceptive use, almost two third (64\%) of study participants had previous experience of contraceptive use and only one-fourth (26\%) of participants were using dual contraceptive method during the survey. The most commonly used contraceptive was injectable (43.5\%) followed by pills (21.4) and implant (19.2\%). Reasons for choosing particular method were, convenience (34.4\%), being used secretly (26.9\%), no need of more children $(20.4 \%)$ and used as a dual protection $(9.7 \%)$

Regarding to HIV related features of participants, most $67(47.2 \%)$ had a CD4 count $\geq 500$ cells/mm3 and 12(8.5) had $<200$ cells/mm3 CD4 count. More than three-fourth (72.7\%) participants' partners tested for HIV and majority (81.3\%) were sero-positive. Majority of participants, 243(78.9\%) disclosed their HIV status to their partner. Around one-fourth of participants $(24.4 \%)$ changed their partner since their diagnosis. The main reason for changing sexual partner were divorce (34.7\%), partner death $19(25.3 \%)$ and spousal rejection $16(21.3 \%)$. On the other hand, majority of participants $(89.0 \%)$ had not been treatment for STI's since their HIV diagnosis (Table 2).

Factors associated with contraceptive use 
First we carried out binary logistic regression to select variables having association with contraceptive use. Then, we retained nine variables for multivariate analysis.

After adjusting confounding factors, maternal age, drinking habit, earlier contraceptive use experience, HIV status disclosure to sex partner, and having sexual activity in the last six months were significant in multivariate logistic regression. Age was positively associated with contraceptive use. Women with younger age (15-34) years old were three times more likely to use contraception (AOR $=3.089,95 \% \mathrm{Cl}$ : 1.591-5.999) than their counter parts i.e.35-49 years old. Likewise, HIV status disclosure to sex partner was positively associated with contraceptive use.HIV positive women who disclosed their status to their sex partners were almost three times more likely to use contraception (AOR $=2.759,95 \% \mathrm{Cl}: 1.142-6.663)$ than their counterparts. Similarly, earlier contraceptive use history was positively associated with contraceptive use. Women who had previous contraceptive use experience almost three times more likely to use contraception $(\mathrm{AOR}=3.361,95 \% \mathrm{Cl}$ : $1.677-6.736)$ than their counterparts.

Having Sexual activity in the last six months also was positively associated with contraceptive use. Women who had sexual activity in the last six months were almost 5 times more likely to use contraception (AOR $=5.451,95 \% \mathrm{Cl}: 2.724-10.908)$ than their counter parts. On the other hand drinking habit was negatively associated with contraceptive use. HIV positive women who had drinking habit were almost 4 times less likely to use contraception $(A O R=4.351,95 \% \mathrm{Cl}: 1.824-10.379)$ than women who did not have drinking habit (Table 3 )

\section{Discussion}

Contraceptive use issue among women enrolled in HIV care and treatment programs in the study area has important implications for the health of women and their infants. The current study stated that overall use of contraception among HIV positive reproductive age women was $38.3 \%$. The finding was consistent with the study done in Addis Ababa (39.4\%)[19], (36.3\%)[20]. On the other hand, the finding of the current study was lower than evidence from Lusaka, Zambia (69\%)[21], North West Ethiopia (47.7\%) [22], Kabale, Uganda (55.1\%)[23],Ireland(55\%)[24] Addis Ababa Ethiopia(43.6\%)[25], Tanzania(54\%) [26],Gondar ,Ethiopia(50\%)[27]. The low use in this study might be due to lack of integration between ART and family planning units. However, prevalence of this study was higher than the study done in Southwestern Uganda (27.8\%)[28], western Africa (8\%)[24]. Prevalence variation might be due socio demographic and cultural differences of the study population.

Many factors affected contraceptive use in the current study. Among these factors, HIV positive women with younger age (15-34) were more likely to use contraceptive method as compared with their counter parts (45-49). The finding is similar to the study done in Ethiopia and Uganda [22, 27, 28]. The possible explanation could be most of young women fear to become pregnant due to social and economic constraints in low-income countries like Ethiopia. Another possible explanation could be that younger women could have more information access than older women related to the benefits of contraceptive use. 
Similarly, HIV positive women with earlier contraception use history were more likely to use contraception than their counterparts. The finding is incongruent with studies done in northwest Ethiopia[22, 29],South East Ethiopia, Uganda[30].The possible explanation could be due to earlier contraceptive use history could help the women in understanding the methods and minimizing the fears concerning the side effects and myths heard about contraception. On the other hand, HIV positive women who disclosed their HIV status to their partners had higher odds of using contraception. Similar findings reported in studies from Ethiopia, Kenya, Nigeria and Zambia [17, 21, 31, 32]. This highlights that disclosure of HIV status to a sexual partner might ease communication between sexual partners to make decision about reproductive issues including contraceptive use. This might be important to get support from family and discussion can clarify uncertainties about contraceptives and possibly to increase confidence of women.

HIV positive women having drinking habit had lower odds of contraceptive use. The result is in line with the study conducted in Uganda[23]. Terplan et al.[33] showed that women with opioid and other substance use disorders used contraception less often than non-drug-using, including alcohol, comparison populations $56 \%$ vs. $81 \%$, respectively. This might be that substance use could affect the memory of women i.e., the woman might forget to take daily oral contraceptive method or condom use. This could lead to unplanned pregnancy and sexually transmitted infections.

\section{Conclusion}

Prevalence of contraceptive use was low in the study area. Injectable are the most preferred method of contraception while convenience to use is the major reason for contraceptive use. Among a number of socio-demographic factors, age, drinking habit, earlier contraceptive use experience, HIV status disclosure to sexual partner and having sexual activity in the last six month were among the independent predictors of contraceptive use. Integrating family planning services and ART service would increase the uptake of contraceptive use. Efforts should be made create better sexual and reproductive health services for HIV positive women to practice their reproductive right in planned and safe way.

\section{Abbreviations}

AIDS:Acquired Immunodeficiency Virus Syndrome; ART:Anti-Retroviral Therapy; BDU:Bahir Dar University; CMHS:Collage Of Medicine And Health Science; FHRH:Felege Hiwot Referral Hospital; HAART:Highly Active Anti-Retroviral Therapy; HIV:Human Immunodeficiency Virus; IUD:Intra Uterine Device; MTCT:Mother to Child Transmission; PMTCT:Prevention of Mother to Child Transmission; STI:Sexually Transmitted Infection; SPSS:Statistical Package For The Social Sciences; AOR:Adjusted Odds Ratio;Cl:Confidence Interval.

\section{Declarations}

\section{Ethics approval and consent to participate}


Ethical clearance obtained from Bahir Dar University, department of nursing research committee and college of health science institutional review board. Each study participant was adequately informed about the aim of the study and anticipated benefit and risk of the study by their data collector. Written consent sought from all study participants for protecting autonomy and ensuring confidentiality.

\section{Consent for publication}

Not applicable.

\section{Availability of data and materials}

The data of this study can't be shared publically due to presence of sensitive (confidential) participants' information.

\section{Competing interests}

There are no competing interests amongst authors

\section{Funding}

Not applicable

\section{Authors' contributions}

All authors conceived and designed study. TA, analyzed, interpreted data and drafted the manuscript for important intellectual content. TT reviewed the manuscript.DJ, GM, MA and GT completed data collection and entry. All authors read and approved the last manuscript.

\section{Acknowledgements}

We would like to thank HIV positive women at Felege Hiwot Referral Hospital for their willingness to take part in the study. We would like also to acknowledge data collectors and supervisors who worked carefully during the data collection process .Our appreciation will also go to Felege Hiwot Referral Hospital staffs for their cooperation to give full information about the study area and study subjects.

\section{References}

1. UNAIDS, Joint United Nations Programme on HIV/AIDS<global-AIDS-update-2016_en.pdf>. 2016.

2. UNAIDS, Joint United Nations Programme on HIV/AIDS https://www.unaids.org/en/resources/documents/2018/unaids-data-2018. 2018.

3. Girum et al., Trend of HIV/AIDS for the last 26 years and predicting achievement of the 90-90-90 HIV prevention targets by 2020 in Ethiopia: a time series analysis. BMC Infectious Diseases (2018) 18:320. 
4. USAID, : Sanders, Rachel. Equity and Access to ART in Ethiopia: Activity Report. Washington,DC: Futures Group, Health Policy Initiative, Task Order 1. 2010.

5. EPHI, Ethiopian Public Health Institution,HIV Related Estimates and Projections forEthiopia. 2017.

6. EPHI, ETHIOPIA POPULATION-BASED HIV IMPACT ASSESSMENT EPHIA 2017-2018<3511 •EPHIASummary-Sheet_v30.pdf>DECEMBER, 2018: ADDIS ABABA,ETHIOPIA.

7. UNAIDS, Family Planning in the Sustainable Development Goals;A Critical Link for Post-2015 Success. 2015.

8. IPPF, Sustainable Development Goals and Family Planning 2020, une 2016, International Planned Parenthood Federation: 4 Newhams Row London SE1 3UZ United Kingdom.

9. USAID, Family Health International,Contraception Cost-Effective For Preventing Mother-To-Child Transmission Of HIV. 2006.

10. MOH, Costed Implementation Plan for Family Planning in Ethiopia, 2015/16-2020, January 2016: ADDI ABABA,ETHIOPIA.

11. Federal Ministry of Ethiopia, Health Sector Transformation Plan(2015/16-2019/20). 2015.

12. Central Statistical Agency (CSA) [Ethiopia] and ICF. 2016. Ethiopia Demographic and Health Survey 2016: Key Indicators Report. Addis Ababa, Ethiopia, and Rockville, Maryland, USA. CSA and ICF.

13. Chersich MF, Wabiri N, Risher K, Shisana O, Celentano D, Rehie T, et al. Contraception coverage and methods used among women in South Africa:A national household survey. SAMJ, S.Afr. med j. 2017;107(4):307-1.

14. Singh S, Darroch JE, Ashford LS. Adding It Up: The Costs and Benefits of Investing in Sexual and Reproductive Health. New York: Guttmacher Institute; 2014. http://deliverforgood.org/wp.

15. UNAIDS: 2014 PROGRESS REPORT ON THE GLOBAL PLAN towards the elimination of new HIV infections among children by 2015 and keeping their mothers alive. 2014.

16. GOVT. OF ETHIOPIA,FAMILY PLANNING 2020 COMMITMENT<Govt.-of-Ethiopia-FP2020Commitment-2017-Update.pdf>, 2017: ADDIS ABABA ETHIOPIA.

17. Gashe, A.a., Contraceptive use and method preference among HIV positive women in Addis Ababa, Ethiopia: a cross sectional survey. BMC Public Health, 2014, 14:566.

18. Kakaire and et al., Factors that predict fertility desires for people living with HIV infection at a support and treatment centre in Kabale, Uganda. Reproductive Health, 2010. 7(21).

19. Wossenyelesh Tamene \& Mesganaw Fantahun (2007) Fertility desire and family-planning demand among HIV-positive women and men undergoing antiretroviral treatment in Addis Ababa, Ethiopia, African Journal of AIDS Research, 6:3, 223-227, DOI: 10.2989/16085900709490418.

20. Shehu AU, Joshua IA, Umar Z. Knowledge of contraception and contraceptive choices among human immunodeficiency virus-positive women attending antiretroviral clinics in Zaria, Nigeria. Sub-Saharan Afr J Med [serial online] 2016 [cited 2019 Dec 17];3:84-90. Available from: http://www.ssajm.org/text.asp?2016/3/2/84/184355. 
21. Hancock and et al., Contraceptive use among HIV-infected women and men receiving antiretroviral therapy in Lusaka, Zambia: a cross-sectional survey. BMC Public Health, (2016) 16:392.

22. Araya et al., The role of counseling on modern contraceptive utilization among HIV positive women: the case of Northwest Ethiopia. BMC Women's Health, 2018. 18(121).

23. Kakaire and e. al., Contraception among persons living HIV with infection attending an HIV care and support centre in Kabale,Uganda. Journal of Public Health and Epidemiology 2010. 2(8): p. 180-188.

24. H S Mitchell and E Stephens, Contraception choice for HIV positive women;Sex Transm Infect: first published as 10.1136/sti.2003.008441. 28 May 2004.

25. Takele Adilo. and et al., "Prevalence and Determinants of Contraceptive Utilization Among Reproductive Age Women Living with HIV/AIDS in Addis Ababa, Ethiopia; A Cross Sectional Study Design". EC Gynaecology 4.3 (2017): 97-112.

26. Damian and e. al., Prevalence and factors influencing modern contraceptive use among HIV-positive women in Kilimanjaro region, northern Tanzania. Contraception and Reproductive Medicine 2018.

3:7.

27. Worke et al., Utilization of contraception among sexually active HIV positive women attending art clinic in University of Gondar Hospital: a hospital based cross-sectional study. BMC Women's Health. 16: p. 67.

28. Winnie, Muyindike, and e. al., ContraceptiveUse and Associated Factors amongWomen Enrolling into HIV Care in SouthwesternUganda. Hindawi publishing corporation, 2012. 2012: p. 9.

29. Gelagay and et al., Factors affecting long acting and permanent contraceptive methods utilization among HIV positive married women attending care at ART clinics in Northwest Ethiopia. Archives of Public Health, 2018. 76(47).

30. Anguzu and et al, Knowledge and attitudes towards use of long acting reversible contraceptives among women of reproductive age in Lubaga division, Kampala district, Uganda. BMC Research Notes, 2014. 7(153).

31. Agnes Mideva Mulongo et al., Factors associated with uptake of dual contraception among HIVinfected women in Bungoma County, Kenya: a cross- sectional study. The Pan African Medical Journal. 2017;28 (Supp 1):2.

32. Chinaeke and et al, Correlates of reported modern contraceptive use among postpartum HIV-positive women in rural Nigeria: an analysis from the MoMent prospective cohort study. Reproductive Health, (2019) $16: 2$.

33. Terplan and et al., Contraceptive use and method choice among women with opioid and other substance use disorders: A systematic review. Prev Med available in PMC, 2016

\section{Tables}

Table1. Socio-demographic, Reproductive and sexual characteristics of participants attending ART clinic in FHRH, Bahir Dar City, North west Ethiopia, 2018. 


\begin{tabular}{|c|c|c|c|}
\hline Variable & Category $(n=308)$ & Frequency & Percent (\%) \\
\hline \multirow[t]{2}{*}{ Age (in years ) } & $15-34$ & 185 & 60.1 \\
\hline & $35-49$ & 123 & 39.9 \\
\hline \multirow[t]{3}{*}{ Religion } & Orthodox & 241 & 78.2 \\
\hline & Muslim & 45 & 14.6 \\
\hline & Others $^{1 *}$ & 20 & 6.5 \\
\hline \multirow[t]{2}{*}{ Educational label } & Educated & 164 & 53.2 \\
\hline & Uneducated & 144 & 46.8 \\
\hline \multirow[t]{2}{*}{ Marital status } & Married & 66 & 21.6 \\
\hline & Unmarried & 241 & 78.4 \\
\hline \multirow[t]{3}{*}{ Occupation } & Unemployed & 184 & 59.7 \\
\hline & Government employ & 63 & 20.5 \\
\hline & Private organization employ & 61 & 19.8 \\
\hline \multirow[t]{2}{*}{ Having Monthly income } & Yes & 181 & 58.8 \\
\hline & No & 127 & 41.2 \\
\hline \multirow[t]{2}{*}{ Drinking habit } & Yes & 260 & 84.4 \\
\hline & No & 48 & 15.6 \\
\hline \multirow[t]{2}{*}{ Number of living children } & No child & 56 & 18.2 \\
\hline & One and above children & 251 & 81.8 \\
\hline \multirow[t]{2}{*}{ Child death } & Yes & 67 & 21.8 \\
\hline & No & 241 & 78.2 \\
\hline \multirow[t]{2}{*}{ Desire to have child in the future } & Yes & 140 & 45.5 \\
\hline & No & 168 & 54.5 \\
\hline \multirow[t]{2}{*}{ Stable sexual relationship } & Yes & 172 & 55.8 \\
\hline & No & 136 & 44.2 \\
\hline \multirow[t]{2}{*}{ Had sexual activity in the last 6 months } & Yes & 172 & 55.8 \\
\hline & No & 136 & 44.2 \\
\hline \multirow[t]{2}{*}{ Number of sexual partners } & None & 103 & 33.4 \\
\hline & One & 181 & 58.8 \\
\hline
\end{tabular}




\begin{tabular}{|c|c|c|c|}
\hline & Two and above & 24 & 7.8 \\
\hline \multirow[t]{2}{*}{ Changed regular sexual partner } & Yes & 75 & 24.4 \\
\hline & No & 233 & 75.6 \\
\hline \multirow[t]{3}{*}{ Reasons for changing } & Partner died & 19 & 25.3 \\
\hline & Divorced & 26 & 34.7 \\
\hline & Rejected by spouse & 20 & 40 \\
\hline \multirow[t]{2}{*}{ HIV status disclosed to Partner } & Yes & 225 & 73.1 \\
\hline & No & 83 & 26.9 \\
\hline
\end{tabular}

$1^{\star}=$ protestant, catholic, Jehovah witness

Table 2.Contraceptive use and HIV related features of participants attending ART clinic in FHRH, Bahir Dar City, North west Ethiopia, 2018. 


\begin{tabular}{|c|c|c|c|}
\hline Variable & Category $(n=308)$ & Frequency & $\begin{array}{l}\text { Percent } \\
(\%)\end{array}$ \\
\hline \multirow[t]{2}{*}{ Ever used contraceptives } & Yes & 197 & 64.0 \\
\hline & No & 111 & 36.0 \\
\hline \multirow[t]{2}{*}{ Currently using contraceptives } & Yes & 118 & 38.3 \\
\hline & No & 190 & 61.7 \\
\hline \multirow[t]{4}{*}{ Types of preferable methods used } & Pills & 66 & 21.4 \\
\hline & Injection & 134 & 43.5 \\
\hline & Implant & 59 & 19.2 \\
\hline & Others $^{1 *}$ & 49 & 15.9 \\
\hline \multirow{5}{*}{$\begin{array}{l}\text { Reason for choosing particular } \\
\text { method }(n=186)\end{array}$} & Convenience & 64 & 34.4 \\
\hline & Cost & 16 & 8.6 \\
\hline & Can be used secretly & 50 & 26.9 \\
\hline & No need more children & 38 & 20.4 \\
\hline & Dual protection & 18 & 9.7 \\
\hline \multirow[t]{3}{*}{ recommend contraception to others } & Yes & 209 & 67.9 \\
\hline & No & 91 & 29.5 \\
\hline & Not certain & 8 & 2.6 \\
\hline \multirow[t]{2}{*}{ Use dual contraceptive method } & Yes & 80 & 26.0 \\
\hline & No & 228 & 74.0 \\
\hline \multirow[t]{2}{*}{ Currently using condom } & Yes & 143 & 46.4 \\
\hline & No & 165 & 53.6 \\
\hline \multirow[t]{2}{*}{ Use of condom in the last 6 months } & consistently & 136 & 44.2 \\
\hline & Not consistently & 172 & 55.8 \\
\hline \multirow[t]{2}{*}{ With whom too often use condom? $(n=139)$} & $\begin{array}{l}\text { regular sexual } \\
\text { partners }\end{array}$ & 76 & 54.7 \\
\hline & casual sexual partners & 63 & 45.3 \\
\hline \multirow[t]{3}{*}{ Recent CD 4 count (cells/mm3) $(n=142)$} & $<200$ & 12 & 8.5 \\
\hline & $200-349$ & 32 & 22.5 \\
\hline & $\begin{array}{l}350-500 \\
\text { e } 14 / 17\end{array}$ & 31 & 21.8 \\
\hline
\end{tabular}




\begin{tabular}{|lllll|}
\hline & $\geq 500$ & 67 & 47.2 \\
\hline Partner tested for HIV & Yes & 224 & 72.7 \\
\hline Partner HIV status(n=224) & No & 84 & 27.3 \\
\hline & Positive & 182 & 81.3 \\
\hline Partner disclosure of your HIV Status & Negative & yes & 42 & 18.8 \\
\hline & No & 65 & 21.1 \\
\hline sexual partner change since diagnosis & yes & 243 & 78.9 \\
\hline & No & 75 & 24.4 \\
\hline reasons for changing sexual partner(n=305) & Partner died & 233 & 75.6 \\
\hline & Divorced & 115 & 26.9 \\
\hline Treated for STI's since HIV diagnosis & Spousal rejection & 108 & 37.7 \\
\hline & Yes & 34 & 11.0 \\
\hline
\end{tabular}

$1^{*}=$ loop, condom, calendar

Table3. Multivariate analysis of factors associated with contraception use among participants attending ART clinic in FHRH, Bahir Dar City, North west Ethiopia, 2018. 


\begin{tabular}{|c|c|c|c|c|c|}
\hline \multirow[t]{2}{*}{ Variables } & \multicolumn{5}{|c|}{ Contraceptive use, n (\%) } \\
\hline & Yes & No & COR $(95 \% \mathrm{CL}$ & AOR $(95 \% C L)$ & $\mathrm{p}$-value \\
\hline \multicolumn{6}{|c|}{ Age of woman of woman } \\
\hline $15-34$ & $92(49.7 \%)$ & $93(50.3 \%)$ & $3.69(2.194-6.208)$ & $3.09(1.591-5.999) *$ & 0.001 \\
\hline $35-49$ & $26(21.1 \%)$ & $97(78.9 \%)$ & Ref & Ref & \\
\hline \multicolumn{6}{|c|}{ Educational level of woman } \\
\hline Educated & $73(44.5 \%)$ & $91(55.5 \%)$ & 1.77(1.105-2.818) & $1.66(0.915-3.025)$ & 0.095 \\
\hline Uneducated & $45(31.3 \%)$ & $99(68.8 \%)$ & Ref & Ref & \\
\hline \multicolumn{6}{|c|}{ Drinking habit of woman } \\
\hline Yes & $79(30.4 \%)$ & $181(69.6 \%)$ & Ref & Ref & \\
\hline No & $39(81.3 \%)$ & $9(18.8 \%)$ & $9.93(4.590-21.474)$ & 4.35(1.824-10.379)* & 0.001 \\
\hline \multicolumn{6}{|c|}{ Previous contraceptive use experience } \\
\hline Yes & $100(50.8 \%)$ & $97(49.2 \%)$ & $5.33(2.992-9.483)$ & $3.36(1.677-6.736) *$ & 0.001 \\
\hline No & $18(16.2 \%)$ & $93(83.8 \%)$ & Ref & Ref & \\
\hline \multicolumn{6}{|c|}{ HIV status of tested Sexual Partner } \\
\hline Positive & $61(33.5 \%)$ & $121(66.5 \%)$ & Ref & & \\
\hline Negative & $24(57.1 \%)$ & $18(42.9 \%)$ & $2.65(1.334-5.243)$ & $1.88(0.885-4.000)$ & 0.101 \\
\hline \multicolumn{6}{|c|}{ HIV status disclosure to partner } \\
\hline Yes & $34(52.3 \%)$ & $31(47.7 \%)$ & 2.08(1.193-3.612) & $2.76(1.142,6.663) *$ & 0.024 \\
\hline No & $84(34.6 \%)$ & $159(65.4 \%)$ & Ref & Ref & \\
\hline \multicolumn{6}{|c|}{ Having stable sexual partner } \\
\hline Yes & $84(48.8 \%)$ & $88(51.2 \%)$ & $2.86(1.754-4.674)$ & $1.85(0.941-3.637)$ & 0.075 \\
\hline No & $34(25.0 \%)$ & $102(75.0 \%)$ & Ref & Ref & \\
\hline
\end{tabular}


Having Sexual activity in the last 6 months

$\begin{array}{llllll}\text { Yes } & 91(52.9 \%) & 81(47.1 \%) & 4.74(2.705-7.605) & \mathbf{5 . 4 5 ( 2 . 7 2 4 - 1 0 . 9 0 8 ) *} & \mathbf{0 . 0 0 0} \\ \text { No } & 27(19.9 \%) & 109(80.1 \%) & \text { Ref } & \text { Ref } & \end{array}$

used condom in the last six months

$\begin{array}{llllll}\text { Yes } & 70(49.0 \%) & 73(51.0 \%) & 2.34(1.462-3.738) & 1.36(0.754-2.468) & 0.304\end{array}$

No $\quad 48(29.1 \%) \quad 117(70.9 \%)$ Ref Ref

\section{${ }^{*}$ p-value $<0.05$}

